\title{
EDITORIAL \\ Possible causes for decreased susceptibility of children to coronavirus
}

\author{
Pediatric Research (2020) 88:342; https://doi.org/10.1038/s41390- \\ 020-0892-8
}

does SARS-CoV. ${ }^{4}$ Thymosin may be considered essential for patients with pneumonia, who are infected with 2019-nCoV.

In conclusion, children may be less susceptible to 2019-nCoV due to differences in ACE activity and in their immunity. Some adjuvant drugs, such as thymosin, may benefit 2019-nCoV patients.

\section{AUTHOR CONTRIBUTIONS}

\section{POSSIBLE CAUSES FOR DECREASED SUSCEPTIBILITY OF CHILDREN TO CORONAVIRUS}

The Health Commission of Hubei Province, China, first announced a cluster of unexplained cases of pneumonia on December 31, 2019. A total of 27 patients were initially reported, ${ }^{1}$ which was followed by a larger-scale epidemic. Next-generation sequencing showed that this was a novel coronavirus (2019-nCoV). However, it is noteworthy that the number of children infected by the coronavirus is limited. ${ }^{2}$ In the two reports in January 2020 regarding youths $<18$ years old ${ }^{3}$ (41 cases) and $<21$ years old ${ }^{4}$ (99 cases), children and teenagers did not appear in these cases. Therefore, why might children be less susceptible to the coronavirus? Here, we provide an analysis of the possible reasons.

The first possible reason pertains to angiotensin-converting enzyme (ACE) activity. One study revealed that children had higher ACE activities. From 4 to 13 years of age, serum ACE progressively increases. After 13 years of age, serum ACE gradually decreases until it reached values for adults. ${ }^{5}$ High-ACE activity documented in the serum of newborns have been proposed as a consequence of the rapid development of lung capillaries after parturition, with capillary endothelial cells being the principal source of circulating ACE. ${ }^{5}$ 2019-nCoV poses a significant public health risk for human transmission via the S-protein-ACE2 binding pathway. ${ }^{6}$ Although elevated serum ACE levels have also been reported to cause active sarcoidosis ${ }^{7,8}$ and idiopathic respiratory distress syndrome, ${ }^{8}$ it is believed that the effect of $2019-n C o V$ on ACE2 may not lead to substantial serious consequences in children. Meanwhile, 2019$\mathrm{nCoV}$ can result in severe and even fatal respiratory diseases for elderly adults, especially those with comorbidities.

The next possible reason is related to immunity. It has been reported that 2019-nCoV is related to a decrease in CD4 cells (\%) in older men when compared with that in women and young men. ${ }^{9}$ CD4 (\%) decreases rapidly in the early childhood and then probably gradually declines throughout the lifespan. CD8 (\%) is maintained or shows a slight increase in elderly adults. ${ }^{9}$ Several studies ${ }^{10}$ showed higher numbers of CD4 cells and lower numbers of CD8 T lymphocytes in children than in adults. Researchers suggested that age-adjusted reference ranges for lymphocyte subsets should be used in pediatric patients. ${ }^{10}$ The changing level of $T$ lymphocytes with age is understood to be related to the development and atrophy of the thymus because the thymus is important for the development of T lymphocytes. 2019-nCoV might mainly act on lymphocytes, especially $\mathrm{T}$ lymphocytes, as
L.Z. made substantial contributions to the conception and design of the study, wrote the paper. and gave final approval of the version to be published. X.L. searched the literature, reviewed, and gave final approval of the version to be published. L.C. searched the literature, identified the target journal and gave final approval of the version to be published.

Publisher's note Springer Nature remains neutral with regard to jurisdictional claims in published maps and institutional affiliations.

Liqin Zhu' ${ }^{1}$ Xiaoqing $\mathrm{Lu}^{2}$ and Lu Chen ${ }^{2}$

${ }^{1}$ Tianjin First Central Hospital, Tianjin, China and ${ }^{2}$ Tianjin Medical University, Tianjin, China

Correspondence: Liqin Zhu (zlq0713@aliyun.com)

1. Chan, J. F. et al. A familial cluster of pneumonia associated with the 2019 novel coronavirus indicating person-to-person transmission: a study of a family cluster. Lancet 395, 514-523 (2020).

2. Ralph, R. et al. 2019-nCoV (Wuhan virus), a novel coronavirus: human-to-human transmission, travel-related cases, and vaccine readiness. J. Infect. Dev. Ctries. 14.01, 3-17 (2020).

3. Huang, C. et al. Clinical features of patients infected with 2019 novel coronavirus in Wuhan, China. Lancet 395, 497-506 (2020).

4. Chen, N. et al. Epidemiological and clinical characteristics of 99 cases of 2019 novel coronavirus pneumonia in Wuhan, China: a descriptive study. Lancet 395, 507-513 (2020).

5. Beneteau-Burnat, B., Baudin, B., Morgant, G., Baumann, F. C. \& Giboudeau, J. Serum angiotensin-converting enzyme in healthy and sarcoidotic children:

6. $\mathrm{Xu}, \mathrm{X}$. et al. Evolution of the novel coronavirus from the ongoing Wuhan outbreak and modeling of its spike protein for risk of human transmission. Sci. China Life Sci. 63, 457-460 (2020).

7. Bender, J. W., Davitt, M. K. \& Jose, P. Angiotensin-I-converting enzyme activity in term and premature infants. Biol. Neonate 34, 19-23 (1978).

8. Rodriguez, G. E., Shin, B. C., Abernathy, R. S. \& Kendig, E. J. Serum angiotensinconverting enzyme activity in normal children and in those with sarcoidosis. J. Pediatr. 99, 68-72 (1981).

9. Nakamura, H. et al. Cellular immunologic parameters related to age, gender, and stage in lung cancer patients. Lung Cancer 28, 139-145 (2000).

10. Kotylo, P. K., Fineberg, N. S., Freeman, K. S., Redmond, N. L. \& Charland, C. Reference ranges for lymphocyte subsets in pediatric patients. Am. J. Clin. Pathol. 100, 111-115 (1993).

\section{REFERENCES} comparison with the reference interval for adults. Clin. Chem. 36, 344-346 (1990). 